\title{
Las infraestructuras viarias de Córdoba a finales del siglo XIX para la enseñanza de las Ciencias Sociales: propuesta didáctica en Educación Primaria
}

The road infrastructure of Cordoba at the end of the nineteenth century for the teaching of Social Sciences: didactic proposal in Primary Education

\author{
Dr. Miguel Jesús LÓPEZ SERRANO \\ Dpto. de Didáctica de las Ciencias \\ Sociales y Experimentales. \\ Universidad de Córdoba \\ mjlopez@uco.es
}

Resumen: En el presente trabajo se expone una breve investigación documental para realizar futuras experiencias didácticas que tengan como objetivo la enseñanza, desde el punto de vista histórico, de las vías e infraestructuras de comunicación (carreteras y caminos, principalmente) como elemento transformador del paisaje o entorno más cercano. Proponemos un esbozo teórico sobre las vías de comunicación existentes en Córdoba y su provincia a finales de la centuria decimonónica, para así tener una fundamentación teórica con la que elaborar una serie de prácticas educativas (itinerarios, mapas históricos, análisis y comparativa de imágenes...) para que, los futuros docentes, puedan entender la importancia de las infraestructuras viarias, no solo como pilares económicos, sociales etc., sino también como elementos configuradores de nuestros territorios más cercanos.

Abstract: In the present work it's exposed a brief documentary research to make future didactic experiences about from the historical point of view as well as the transformation of the routes and communication infrastructures (mainly, roads and ways) like transforming elements of the landscape or surroundings closest. We propose a theoretical outline of the communication routes existing in Córdoba and its province at the end of the nineteenth century, in order to have a theoretical foundation to elaborate a series of educational practices (itineraries, historical maps, analysis and comparison of images ...). 
This way that future teachers can understand the importance of road infrastructures, not only as economic, social factors, etc., but also as configurating elements of our closest territories.

Palabras Clave: Vías de comunicación, Didáctica de las Ciencias Sociales, Medio Ambiente, Educación Primaria.

Keywords: Communication channels, Didactic Social Sciences, Environment, Primary Education.

\section{Sumario:}

I. Introducción.

II. Carreteras, vías y caminos.

III. Antecedentes legislativos.

IV. Las carreteras en la provincia de Córdoba.

V. Conclusiones.

VI. Bibliografía.

Recibido: septiembre de 2019.

Aceptado: noviembre de 2019. 


\section{INTRODUCCIÓN}

En los últimos decenios la importancia del estudio y enseñanza del Medio Ambiente y sus transformaciones ha sido un tema fundamental en las reuniones educativas más vinculantes. La Universidad no ha sido ajena a esta realidad y ha ido incorporando a su oferta académica diferentes grados, a la vez que, las asignaturas de conceptualización ambiental han pasado a formar parte de los planes de estudio de varias titulaciones.

La imagen que tenemos del paisaje es una idea confusa y con múltiples acepciones. Normalmente solemos entenderlo como un recurso que pertenece al patrimonio de las personas y las sociedades a lo largo de la historia. Un legado de carácter histórico, ambiental y social que requiere una atención por parte no solo de la comunidad científica o de las élites gubernamentales, sino de las políticas educativas que tienen la obligación de dotar su estudio con una serie de contenidos sólidos ya que, el paisaje en sí mismo, es una herencia, un bien común de las sociedades que debe ser enseñado desde las edades más tempranas para entender las diferentes transformaciones que ha sufrido a lo largo de la historia.

Teniendo en consideración estas modificaciones, las más destacables están en relación con aspectos variables y casuísticas diversas, podemos enfatizar como elementos reformadores del paisaje las causas económicas que derivan en gran medida de las actuaciones políticas de las distintas administraciones, las causas naturales: incendios, deforestaciones, o en el caso que nos ocupa, la planificación y construcción de vías de comunicación.

Así pues, se hace perentoria la necesidad de que los futuros docentes estén capacitados y capacitadas tanto en materias transversales u optativas de Educación Medioambiental como en la consecución de los objetivos de etapa, área y los contenidos de las diferentes asignaturas que contribuyan a explicar y comprender el concepto del paisaje en el alumnado. A lo largo de la Etapa de Primaria, los y las estudiantes deben ir comprendiendo a la vez que estableciendo las primeras nociones de relación e importancia entre los acontecimientos y los elementos que interactúan en el entorno natural, social... 
Por tanto, este tema va a estar interrelacionado con el área del medioambiente, de la didáctica de las Ciencias Sociales, de la Geografía, entre otras, puesto que su objetivo principal será el de estudiar y comprender los principales elementos $\mathrm{y}$ transformaciones del territorio o paisaje natural.

Es por ello, que creemos que la enseñanza del entorno, debería comenzar desde las edades más tempranas y continuar en las diferentes etapas del sistema educativo español. Se debería motivar no solo al alumnado de los grados de Maestro de Educación Infantil y Primaria, sino también a los pequeños y pequeñas, con el objetivo de que puedan estudiarlo, vivenciarlo y que desarrollen una serie de estrategias que les faculten un entendimiento progresivo, comprendiendo que el respeto hacia los distintos ecosistemas y al cuidado del medio ambiente debe ser un eje vehicular de su formación académica y personal.

Recogemos en estas líneas el fundamento teórico para realizar una futura propuesta didáctica que tenga como objetivo la enseñanza, desde el punto de vista histórico, de las vías de comunicación (carreteras principalmente) como elemento transformador del paisaje o entorno más cercano. Proponemos un esbozo documental sobre las vías y caminos existentes en Córdoba y su provincia para así tener el sustrato con el que elaborar una serie de prácticas educativas (itinerarios, mapas históricos...) con el que, los futuros docentes, puedan entender la importancia de las infraestructuras viarias, no solo como pilares económicos, sociales etc., sino también como elementos trasformadores y configuradores de nuestro territorio.

\section{CARRETERAS, VÍAS Y CAMINOS}

En la España decimonónica al hablar de las infraestructuras con las que estaba dotado el país en materia de comunicaciones tanto terrestres como fluviales, siempre que se oían voces críticas los responsables estatales y técnicos achacaban el retraso con respecto a otros países a cuestiones de índole orográfica:

Esta circunstancia, que forzosamente tiene que originar mayores dificultades que en otros países para la realización de las obras públicas destinadas á comunicar unos pueblos con otros, no impide, sin embargo, que España pueda ostentar una red bastante completa de carreteras y otra de ferrocarriles ${ }^{1}[\ldots]$. (Anuario Estadístico Español, 1888, p. 403).

\footnotetext{
${ }_{1}^{1}$ Anuario Estadístico Español, 1888, p. 403.
} 
La realidad sobre esta afirmación difiere mucho de ser verdad, no obstante, hay que reseñar que si bien el entramado comunicativo no era tan completo como en otros países europeos era lo suficientemente amplio para que estuvieran conectadas la mayoría de capitales de provincia y pueblos por medio de unos caminos que en ocasiones estaban más cercanos a épocas pasadas -presencia de bandolerismo, escasez de señalizaciones, ausencia de mantenimiento, construcción, trazados mal planificados...- que a las vías propias del cambio de siglo.

Observamos pues como en plena restauración borbónica sólo existían en explotación el $49.40 \%$ del total de kilómetros que comprendían las carreteras incluidas hasta el 1 de enero de 1885 en el Plan General. Este recogía un total de 47.719, 735 kilómetros que se estructuraban de la siguiente manera:

\begin{tabular}{|c|c|}
\hline CARRETERAS & No DE KILÓMETROS \\
\hline Explotación & $23.574,336$ \\
\hline Construcción & $4.728,220$ \\
\hline $\begin{array}{l}\text { Construcción } \\
\text { paralizada }\end{array}$ & 140,542 \\
\hline Proyecto aprobado & $2.361,214$ \\
\hline Estudio & $10.855,597$ \\
\hline Sin estudiar & $5.791,741$ \\
\hline Abandonados & 268,085 \\
\hline TOTAL & $47.719,735$ \\
\hline
\end{tabular}

Fuente: Anuario Estadístico Español, 1888, p. 405.

Hay que señalar que según consta en el Anuario Estadístico Español ${ }^{2}$ se consideraban en construcción las obras que se hallaban en curso de ejecución en la expresada fecha; en construcción paralizada, las que estaban suspendidas por haberse rescindido las contratas o haberse agotado el crédito concedido para ellas; en proyecto aprobado, las que tenían estudios definitivamente aprobados, $\mathrm{y}$, por tanto, estaban en disposición de ser construidas inmediatamente que se diera la orden para ello; en estudio, las mandadas estudiar, cuyos proyectos, por tanto, se hallaban sin aprobar; y sin estudiar todas aquellas líneas para las cuales no había proyecto redactado ni orden de formarlo.

En el intervalo de 1868 a 1885 el impulso gubernamental para la construcción y mejora de las vías de comunicación fue tal que en apenas 17 años se construyeron y proyectaron en España $8.506,919 \mathrm{~km}$ gracias a un nuevo marco legislativo conformado tras el Sexenio Revolucionario.

\footnotetext{
${ }^{2}$ Ibídem, p. 405
} 
Figura 1. Mapas de carreteras de España.

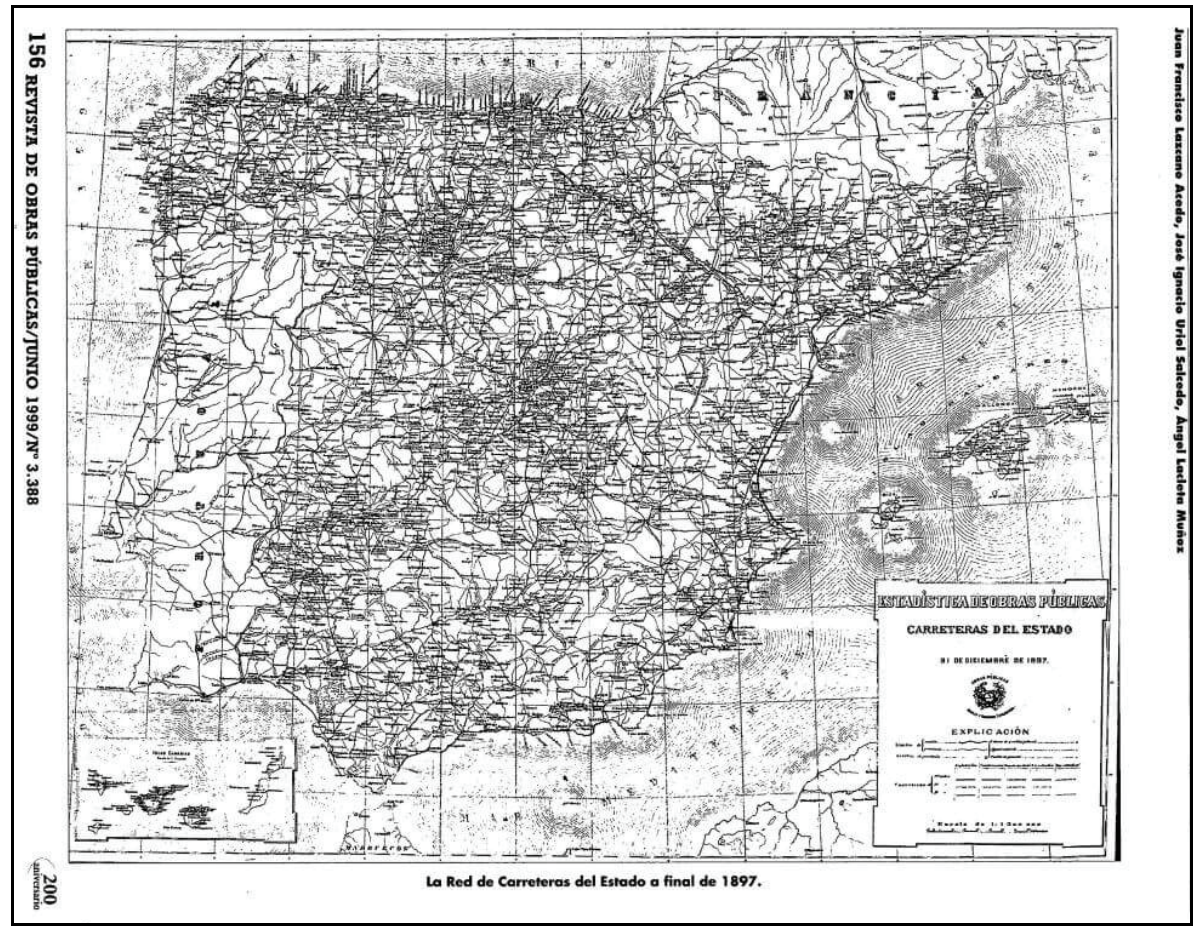

Fuente: Revista de Obras Públicas, № 3388 (1999) 156.

\section{ANTECEDENTES LEGISLATIVOS}

Tras los azarosos primeros decenios del siglo XIX la situación del país necesitaba de un paréntesis para la reorganización de todos los sistemas estatales; en el caso que nos ocupa, fue a raíz del ascenso al poder de los liberales cuando comienza a plantearse y regularse las normativas en materia de comunicaciones creándose por R.D. de 30 de abril de 1835 el cuerpo de Ingenieros Civiles, la ley que autorizaba la Expropiación Forzosa el 17 de julio de 1842, la creación de las Ordenanzas para la regulación de la Policía de carreteras en septiembre de 1842 y la división de la península en 10 distritos. Pero habrá que esperar hasta la publicación en 1845 de la Instrucción para promover y ejecutar obras públicas en España para poder hablar de un auténtico plan legislativo homogéneo.

Un apartado importante que recoge la Instrucción y que, a la postre, era causante de la mayoría de los problemas fue la cuestión de la financiación de 
las obras, para ello se distingue una clasificación y dependiendo de ella la costearían los organismos pertinentes, Estado, Diputaciones, Ayuntamientos, Iniciativa Privada ${ }^{3}$, finalmente plasmada en la Ley Arteta de 1851, muy cercana de los planteamientos borbónicos divisorios pero innovadora en la cuestión económica. La Ley de 1851 estipulaba quién debía costear las obras dependiendo de la tipología de los caminos:

Figura 2.

\begin{tabular}{|l|c|c|c|}
\hline & Estado & Diputación & Otros \\
\hline Carreteras Generales & $100 \%$ & ----------- & ---- \\
\hline Carreteras Transversales & 30 y máximo del $50 \%$ & 50 y máximo $70 \%$ & ---- \\
\hline Carreteras Provinciales & máximo 30\% & 70 y el $100 \%$ & ---- \\
\hline Caminos Vecinales & ----------- & ----------- & $100 \%$ \\
\hline
\end{tabular}

Fuente: Gómez Mendoza, 1991, p. 181, y Cuéllar Villar, 2003, p. 91.

Tan sólo cinco meses después entrará en vigor la Ley Moyano de 1857, la cual establecía ya una división lógica en el entramado viario, catalogando las vías como de servicio público, entre ellas, las de primer, segundo y tercer $\operatorname{orden}^{4}$, y las de servicio particular, eran aquellas referidas a cualquier utilidad industrial. Así pues, con esta normativa se pretendía fomentar la iniciativa estatal en la construcción del mapa viario parcelando previamente todo el coste según la clasificación e importancia de las vías. Pero esta medida no estuvo exenta de polémica. Muchas voces se alzaron en contra de ella por lo perjudicial que iba a ser para el país; se creía que tras la clasificación de las carreteras transversales que se costearían a medias con las provincias para estimular la construcción, se produciría el efecto contrario, ya que los diferentes términos dirigirían todas sus iniciativas para conseguir que el Gobierno declarase transversales todas las líneas y que así fueran costeadas, en parte, por el Estado. Obtenida la categoría, con un poco más de esfuerzo no sería difícil

${ }^{3}$ CUÉLlAR VILLAR, D., Los Transportes en el Sureste Andaluz (1850-1950): Economía, empresa y territorio. Fundación historia de los ferrocarriles, Madrid 2003, pp. 89 y ss., y del mismo autor "Las carreteras en el sureste andaluz (1850-1950): organización del territorio y formación del capital", Actas del III Congreso de Historia de Andalucía. Andalucía Contemporánea, T. II, vol. 12, Córdoba 2003. pp. 91-96. A. GÓMEZ MENDOZA, "Las obras públicas, 1850-1935”, en COMÍN COMÍN, F., y MARTÍN ACEÑA, P. (dir.), Historia de la Empresa Pública en España. Madrid 1991, pp. 179-184.

${ }^{4}$ Las carreteras de primer orden unían Madrid con el resto de las capitales de provincia, los departamentos de Marina y Aduanas marítimas habilitadas para el comercio, etc. Las de segundo orden comunicaban dos capitales de provincia, las que comuniquen poblaciones con más de 10.000 habitantes con una carretera de primer orden o un ferrocarril, etc., las de tercer orden, serían aquellas no clasificadas entre los dos primeros grupos. 
convertirla en general, para que estuvieran a cargo de la Administración ${ }^{5}$. Tal era su pretensión que recogía la absorción completa en lo que a las vías de comunicación se refiere por parte del estado, en consonancia, con las tendencias centralizadoras en administración.

En 1860, se aprueba por R.D. de 7 de septiembre el Plan General de Carreteras para la Península e Islas adyacentes que intentaba solucionar la desconfianza que había en los intereses locales de poder demostrar la verdadera necesidad e importancia de una carretera, o sus pretensiones de elevar la línea de comunicación a un orden que por sus condiciones no le correspondía. Para lograr la construcción de una vía o un ramal necesaria solamente a una comarca o provincia con una categoría superior a la que le correspondía, se le suponía formando parte de grandes líneas entre dos puntos para todo género de relaciones, faltando así a la base de la ley de carreteras. Comprobamos que con la aprobación del plan general se pretendía garantizar la seguridad de construir las líneas más importantes, el medio de evitar el empleo de los fondos públicos en la ejecución de obras que no sean de verdadero interés general, la facilidad de adoptar un plan seguro y justo para el desarrollo del sistema de comunicaciones y como consecuencia el poder acelerar la realización completa de la red. El plan aprobado en 1860 comprendía 77 carreteras de primer orden, 179 de segundo y 299 de tercero; con una longitud total de 34.353 kilómetros, distribuidos de la siguiente manera ${ }^{6}$ :

Figura 3

\begin{tabular}{|c|c|c|c|}
\hline \multirow{4}{*}{ Carreteras de } & $1^{e r}$ orden & $13.608 \mathrm{Km}$. & \multirow{4}{*}{2000 mill. } \\
\hline & $2^{\circ}$ orden & $10.563 \mathrm{Km}$. & \\
\hline & $3^{\text {er }}$ orden & $10.182 \mathrm{Km}$. & \\
\hline & Total & $34.353 \mathrm{Km}$. & \\
\hline
\end{tabular}

Fuente: Revista de Obras Públicas, 8, tomo I (19) (1860) 228.

Con el triunfo de "La Gloriosa" se abre un periodo nuevo en materia legislativa en el que se cuestiona el intervencionismo estatal, se pretende erradicar en la medida de lo posible el sistema de construcción y subvenciones del periodo anterior y fomentar la descentralización junto con la iniciativa empresarial privada. El punto de partida que marca estas ideas del Sexenio Revolucionario será el Decreto Ley de 14 de noviembre de 1868 que catalogaba el monopolio estatal como un mal endémico para el país. La Ley establecía

\footnotetext{
${ }^{5}$ Revista de Obras Públicas, Sobre el proyecto de Ley presentado a las Cortes por el Gobierno, clasificando los caminos ordinarios o carreteras, 1857, 5, tomo I (11) 121-124.

${ }^{6}$ Ibidem, 1860, 8, tomo I (19) 227-230; y 1860, 8, tomo I (20) 233-236.
} 
que las carreteras de servicio público pudieran ser construidas con capitales particulares mediante un sistema de concesiones sin subvención. Muestra clara del nuevo pragmatismo revolucionario sería la multitud de proyectos de obras desechados al considerarlos irrelevantes, en parte por los errores de los diferentes planes anteriores y por la creencia de que una vez establecido el ferrocarril muchas carreteras carecían de sentido y utilidad.

Hay que destacar que revisando la trayectoria legislativa pocas fueron las modificaciones que se plantearon durante la Restauración; entre ellas podemos destacar, una nueva Ley de Carreteras sancionada el 4 de mayo de 1877 por Alfonso XII. Esta Norma tiene un marcado carácter económico: establece en su artículo $2^{\circ}$ que las carreteras podrán ser costeadas por el estado, las provincias, municipios, particulares y con fondos mixtos; en cuanto a la clasificación de las vías sigue manteniendo vigente el esquema del Plan de 1860 pero con algunos pequeños matices en cuanto a los requerimientos necesarios que se deben cumplir para catalogar las vías ${ }^{7}$. Las novedades más importantes radican en la financiación introduciendo la posibilidad de la construcción por iniciativas particulares, siempre y cuando las carreteras sean de servicio público y se construyan mediante concesiones -otorgadas por el Ministerio de Fomento, cuyo titular era Francisco de Borja Queipo de Llano- para reintegro de los capitales invertidos y sin ninguna subvención por parte del Estado. También la ley abre la posibilidad de costear la ejecución de las obras a través de fondos mixtos, siempre y cuando la subvención procedente del Estado no exceda la cuarta parte del presupuesto y si es en el caso de las Diputaciones, la cuantía subvencionada no puede ser más de la tercera parte del presupuesto aprobado.

\footnotetext{
${ }^{7}$ A la hora de establecer las categorías de las carreteras se establecen una serie de criterios a cumplir:

"Art. 4". De las Carreteras costeadas por el Estado:

- ${ }^{e r}$ Orden: Las que desde Madrid se dirijan a las capitales de provincia y a los puntos más importantes del litoral y de las fronteras. Las que partiendo de algún ferrocarril o carretera de primer orden conduzcan a alguno de los puntos designados en el párrafo anterior. Las que enlacen dos o más ferrocarriles pasando por un pueblo cuyo vecindario no baje de las 15.000 almas. Las que unan dos o más carreteras de primer orden pasando por alguna capital de provincia o centro de población de más de 20.000 almas.

$-2^{\circ}$ Orden: Las que pongan en comunicación dos capitales de provincia. Las que enlacen un ferrocarril con una carretera de primer orden. Las que partiendo de un ferrocarril o de una carretera de primer orden, terminen en un pueblo que sea cabeza de partido o que tenga más de 10.000 almas. Las que en las Islas Baleares pongan en comunicación a la capital con otros puntos maritimos.

$-3^{\text {er }}$ Orden: Las que sin tener ninguno de los caracteres expresados en los artículos anteriores interesen a uno o más pueblos, aún cuando no pertenezcan a la misma provincia. Las incluidas en el párrafo tercero del art. $5^{\circ}$ siempre que así se juzgue conveniente como resultado de las informaciones que se hagan con arreglo a las prescripciones de la presente ley". Gaceta de Madrid, 6/V/1877.
} 
Esta ley y su marcado carácter aperturista dio posibilidad a que se recogieran a su amparo, un poco difuso, multitud de ordenanzas que con frecuencia atrasaban los proyectos y concesiones aprobadas. Por ello, el Ministro de Fomento, Eugenio Montero Ríos, mandó redactar por R.D. de 16 de septiembre de 1886, un Decreto sobre la redacción de un nuevo plan de carreteras en España que pretendía racionalizar los proyectos que aún estaban sin ejecutar, ordenando a los Ingenieros Jefes de las provincias que procedieran con toda la urgencia que sea compatible con el ordinario servicio a la redacción del plan de carreteras generales, dentro de los límites de sus provincias respectivas que prudencialmente calculen que podrán construirse en un periodo de veinte años. Lo que se pretendía era crear una carta general de España para poder estudiar las necesidades de las carreteras, los centros de toda clase de producción y de consumo, los ferrocarriles existentes como los proyectados, las canteras construidas y en construcción ${ }^{8}$.

\section{LAS CARRETERAS EN LA PROVINCIA DE CÓRDOBA}

La situación viaria que nos encontramos tras el golpe revolucionario y el reinado de Alfonso XII, no alterará en extremo el mapa de las comunicaciones en la provincia; si hasta el momento, y a pesar de la aplicación de los diversos planes generales de carreteras las condiciones de las comunicaciones eran en extremo lamentables y no sólo nos referimos a los caminos rurales sino que como atestiguan diversos viajeros de la época incluso las vías de primer orden destacaban por su pésimo estado, en poco tiempo variará el escenario 9 .

A la altura de 1868 el sistema viario español había sido construido siguiendo los esquemas tradicionales borbónicos: una red de carreteras radial focalizada a la conexión de la capital con las urbes más importantes del reino, con las característica principal de estar fomentadas en demasía por los intereses comerciales e industriales y con un proceso de construcción rápido y precario en las preparaciones técnicas imprescindibles para su conservación, lo que, al tiempo, provocaría que las carreteras erigidas se vieran en época de lluvias intransitables y que los focos rurales estuvieran alejados del entramado comercial debido a la falta de caminos transitables por los que colocar sus mercancías.

La nueva perspectiva que se abría en el país a raíz de los cambios acaecidos por la septembrina estaría marcada por un nuevo enfoque más práctico que sirviera de trasfondo pacificador a la par que impulsara el desarrollo en ámbitos más localistas mediante la construcción prioritaria de vías secundarías, terciarias y

\footnotetext{
${ }^{8}$ Revista de Obras Públicas, Decreto sobre la redacción de un nuevo plan de carreteras en España, 1886, 34, tomo IV, boletín, (18) 150-152.

${ }^{9}$ Véase, LÓPEZ ONTIVEROS, A., Caracterización geográfica de Andalucía según la literatura viajera de los siglos XVIII y XIX, Córdoba 2001.
} 
caminos rurales para garantizar e impulsar el progreso de los núcleos más aislados a través de un nuevo entramado comunicativo más arborescente que radial, construido por grandes masas de trabajadores que lograban un sustento con los que mantener a sus familias y así el estamento político desviaba su atención ante los caóticos tiempos que se estaban viviendo tras la expulsión de la reina.

El nuevo consistorio resultante tras los hechos de septiembre, encabezado por Rafael Bastida y Herrera, Conde de Robledo de Cardeña, ve en la realización de obras públicas la solución más inmediata y factible para dar un modus vivendi a los campesinos y ciudadanos que no tenían ningún tipo de recursos, propiciando, como hemos dicho, la construcción de obras públicas. Entre ellas algunos proyectos de carreteras y caminos financiados, si fuera necesario, como finalmente ocurrió, por los mayores contribuidores de la ciudad. Esta solución de emergencia emanaba de la Ley Arteta de 1851 que daba la independencia económica a los municipios para sufragar incluso hasta el $100 \%$ la construcción de los caminos.

Así vamos a comprobar como en unos pocos años la red viaria cordobesa va a transformar su imagen sobre todo a través de dos impulsos: la carestía de trabajo de grandes masas de jornaleros y los nuevos planes de carreteras dictaminados por el gobierno central. En 1868 observamos como los proyectos de construcción de nuevas carreteras son escasos y centrados en las vías que no eran de primer orden, tendencia que se inició en 1855 , y que se fomentaría en el futuro por las nuevas élites gubernativas nacionales y locales, por lo que las medidas que encontramos en los diversos documentos consultados nos muestran un claro favoritismo a la construcción de caminos de tercer orden y vías comarcales en la provincia cordobesa. Durante las últimas décadas de la centuria decimonónica los trabajos en la red viaria impulsados por las diversos gobiernos y corporaciones se centraban casi con un carácter de exclusividad en fomentar la red de comunicaciones del sur provincial - zonas de la subbética, campiña sur y campiña este- quienes, del cómputo total de las obras desarrolladas, estas regiones consiguieron un 53\% de los proyectos en contraposición con la zona meridional que apenas sin alcanzaban el $12.8 \%$.

Figura 4.

\begin{tabular}{|c|c|}
\hline $\begin{array}{c}\text { Campiña Sur } \\
\text { Subbéticas }\end{array}$ & $3,80 \%$ \\
\hline Vega del Guadalquivir & $12,80 \%$ \\
\hline Alto Guadiato & $12,80 \%$ \\
\hline $\begin{array}{c}\text { Sierra Morena } \\
\text { Valle de los Pedroches } \\
\text { Valle del Guadiato }\end{array}$ & $20,50 \%$ \\
\hline
\end{tabular}

Fuente: Elaboración propia. 
Como observamos, más de la mitad de los recursos gubernamentales se destinan a la mejora de las comunicaciones entre las poblaciones del sur provincial, quienes suman 21 concesiones de los 39 presupuestadas en estos 17 años, siendo todas ellas de segundo y tercer orden, respectivamente, seguida por la zona norte con 8 proyectos. Los datos expuestos en la figura 5, son totalmente comprensibles y coherentes con las nuevas perspectivas que durante estos años se estaban reorganizando, pues no hay que olvidar que estas áreas -sur y norte provincial- son las que presentan la orografía más compleja y problemática, lo que a su vez ocasionaba que las necesidades fueran mayores por las carencias que por este respecto sufrían. Muchos son los testimonios que recogen que en épocas invernales o simplemente con temporales lluviosos estas carreteras montesas se hacían prácticamente intransitables sin olvidar, que, en muchos casos, ni existían los caminos que conectaban diversas poblaciones.

Como vemos, la pauta principal de acción de las fuerzas políticas locales cordobesas fue la de dotar de una red básica de caminos a aquellas zonas que hasta la fecha no la tenían, con el fin de ubicar dichas poblaciones en la red comercial para lograr un desarrollo tanto local como provincial, dando prioridad absoluta a las comunidades poblacionales más aisladas. En su mayoría las construcciones eran trozos no demasiados extensos cuya elección estaba fijada en base al presupuesto y la utilidad.

Figura 5. Carreteras proyectadas en la provincia de Córdoba durante el periodo $1868-1885$

\begin{tabular}{|c|c|c|c|c|}
\hline $\boldsymbol{A} \tilde{N} \boldsymbol{O}$ & NOMBRE DEL CAMINO & CLASE & PRESUPUESTO & KILÓMETROS \\
\hline \multirow[t]{2}{*}{1868} & $\begin{array}{l}\text { Carretera de los Arenales hasta } \\
\text { la huerta de la Aduana }\end{array}$ & & & \\
\hline & Carretera Córdoba a Trassierra & & & \\
\hline \multirow{7}{*}{1869} & $\begin{array}{l}\text { Cabra de Cabra, de Monturque a } \\
\text { Alcala la Real }\end{array}$ & $3^{\text {er }}$ Orden & & \\
\hline & $\begin{array}{l}\text { Trozos } 9 \text { y } 10 \text { de la carretera } \\
\text { Córdoba a Baena }\end{array}$ & $2^{\circ}$ Orden & & \\
\hline & $\begin{array}{l}3 \text { primeros trozos de Cabra a } \\
\text { Castro del Río }\end{array}$ & $3^{\text {er }}$ Orden & & \\
\hline & $\begin{array}{l}\text { Trozo de Monturque a Belarcazar } \\
\text { de la carretera de Villanueva del } \\
\text { Duque a Castuera }\end{array}$ & $3^{\text {er }}$ Orden & 231246,113 & \\
\hline & $\begin{array}{l}\text { Cabra a Montón al confín de la } \\
\text { provincia }\end{array}$ & $3^{\text {er }}$ Orden & & \\
\hline & Trozos 4,5 y 6 de Cabra a Castro & $3^{\text {er }}$ Orden & & \\
\hline & $\begin{array}{l}\text { Trozos } 10,11 \text { y } 12 \text { de } \\
\text { Bujalance a Montilla }\end{array}$ & $3^{\text {er }}$ Orden & & \\
\hline
\end{tabular}




\begin{tabular}{|c|c|c|c|c|}
\hline & $\begin{array}{l}\text { Puente mixto de fábrica y } \\
\text { hierro en la carretera del } \\
\text { ferrocarril de Córdoba a Sevilla }\end{array}$ & & 309557,913 & \\
\hline \multirow{3}{*}{1870} & $\begin{array}{l}\text { Suprimir carretera de Aguilar al } \\
\text { límite de Sevilla, entre aquel } \\
\text { punto y Puente Genil }\end{array}$ & $3^{\text {er }}$ Orden & & \\
\hline & $\begin{array}{l}\text { Villanueva del Duque a } \\
\text { Pozoblanco }\end{array}$ & $3^{\text {er }}$ Orden & 117125,25 & \\
\hline & Trozos 8,11 y 12 Jaén a Córdoba & $2^{\circ}$ Orden & & \\
\hline 1871 & $\begin{array}{l}\text { De Puente Genil al río Genil } \\
\text { (Puente Genil al límite de Sevilla) }\end{array}$ & $3^{\text {er }}$ Orden & & \\
\hline 1872 & $\begin{array}{l}\text { Ventas de Cárdenas al río Yeguas } \\
\text { (Andújar a Villanueva del Duque) }\end{array}$ & $3^{\text {er }}$ Orden & 765078,89 & 29,708 \\
\hline 1873 & $\begin{array}{l}\text { Villanueva de Córdoba a Ventas } \\
\text { de Cárdenas (Andújar a } \\
\text { Villanueva del Duque) }\end{array}$ & $3^{\text {er }}$ Orden & 484405 & 26,977 \\
\hline \multirow[t]{2}{*}{1875} & $\begin{array}{l}\text { Montoro al confín de la } \\
\text { provincia (Lucena a Rute) }\end{array}$ & $2^{\circ}$ Orden & & 6,994 \\
\hline & Trozo $1^{\circ}$ de Lucena a Rute & $3^{\text {er }}$ Orden & & \\
\hline 1885 & Trozo $2^{\circ}$ Bujalance a Villa del Río & & 86547,23 & 7,872 \\
\hline \multirow{3}{*}{1877} & Cabra a Nueva Carteya & $3^{\text {er }}$ Orden & & \\
\hline & $\begin{array}{l}\text { Andújar a Villanueva de Córdoba } \\
\text { y las Ventas de Cardeñas }\end{array}$ & $3^{\text {er }}$ Orden & & \\
\hline & Carretera de los Arenales & & & \\
\hline 1885 & Trozo $2^{\circ}$ Bujalance a Villa del Río & & 86547,23 & 7,872 \\
\hline
\end{tabular}

Fuente: Actas Capitulares, Diario de Córdoba, BOPCO, Revista de Obras Públicas... período 1868-1885. Elaboración propia.

Estos tramos salían a subasta y el contratista final recibía ayudas de la diputación y en algunos casos concretos del gobierno nacional, una muestra de cómo se realizaban los proyectos y su ejecución lo exponemos en el análisis de un ramal proyectado en la carretera de Bujalance a Villa del Río de $2^{\mathrm{a}}$ categoría.

El presupuesto total para la construcción de los 7872 metros era de 86.247, 23 pesetas de los cuales la diputación provincial sufragaba el $49,9 \%$ o lo que es lo mismo 43.123,61 pesetas. El contratista estaba sujeto a concluir las obras en un periodo que no podía sobrepasar los dos años, teniendo que pagar un depósito provisional de 4.400 pesetas y empezar las obras en un tiempo máximo de 60 días tras formalizar el depósito.

Los materiales a utilizar, hay que tener en cuenta que las carreteras que hoy día conocemos -basadas en un lecho de alquitrán- empezaron a fabricarse a principios del siglo XX, eran de arenisca roja (procedente del Castillo de la 
Aragonesa, a orillas del Guadalquivir), piedra para firme y hormigón (extraídas de los olivares del Estacar y de la Heredad, la arena se obtiene de los márgenes del Guadalquivir y la cal se obtendrá de la población de Villa del Río. Como observamos la adquisición de los materiales se hacía en localidades o ubicaciones cercanas con el fin de abaratar los costes por cuestiones de transporte, lo cual supondría, a pesar del incipiente establecimiento del ferrocarril, una subida en los gastos presupuestarios bastante considerable.

Las labores de construcción se dividían en diferentes operaciones como la explanación del terreno, las diversas obras de fábrica necesarias, el afirmado del terreno, obras accesorias y finalmente la conservación y el acopio, tanto de la calzada como de los materiales.

Los trabajadores en su mayoría se contrataban entre sectores de la población de alto riesgo, como los parados y personas sin ningún tipo de recursos ${ }^{10}$, los presos y el ejército que suponían una mano de obra barata y abundante para rebajar costos y finalmente mano de obra cualificada. Los sueldos variaban entre los 3.2 reales por día que cobraba un peón hasta los 14 reales/día que recibían los trabajadores especializados.

Figura 6. Carretera de Bujalance a Villa del Río.- $2^{\circ}$ trozo.

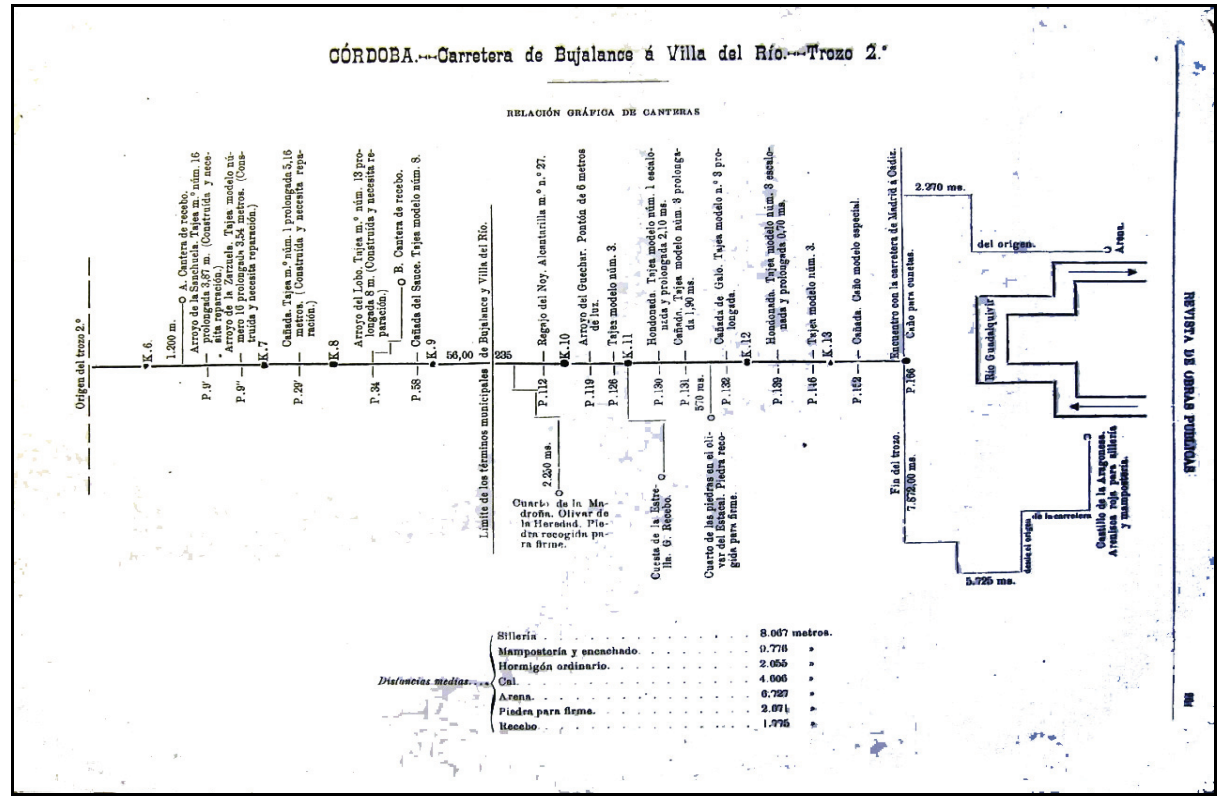

Fuente: Revista de Obras Públicas, tomo 15 (1885) 261.

${ }^{10}$ A.C. del día 8 de enero de 1868. 
Pasemos ahora a analizar la realidad de la situación de la provincia de Córdoba en comparación con una muestra a nivel nacional y andaluz, entre la década de los sesenta hasta los ochenta del siglo XIX (véase figura 7), en la que podemos contemplar el crecimiento que durante este periodo sufrió la ciudad de la Mezquita con respecto a las realidades de otras provincias, pudiendo observar objetivamente que posición e importancia albergaba en el panorama nacional. Lo primero que destacamos al observar los resultados es como en apenas 21 años, la superficie viaria de la provincia prácticamente se duplica, pasando de los 355,309 km de 1867 a los 554,379 km de 1888 . No obstante, tenemos que reseñar que estos datos a pesar de ser totalmente objetivos, pueden inducir a errores de apreciación ya que en 1867 y en años anteriores no se recogía el kilometraje de las carreteras provinciales en uso por lo que el crecimiento deducimos que fue sensiblemente menor, aunque bastante relevante si observamos los kilómetros de las vías de segundo y tercer orden, cuyo crecimiento aumenta entre un $1.4 \%$ y un $1.5 \%$, a diferencia del caso de las de primer orden cuya aumento es prácticamente nulo en 20 años.

Figura 7. Evolución de los kilómetros en la provincia de Córdoba 1861-1888

\begin{tabular}{|c|c|c|c|c|c|}
\hline & $\begin{array}{c}\text { Carreteras } \\
\text { 1 orden }\end{array}$ & $\begin{array}{c}\text { Carreteras } \\
\text { 2 orden }\end{array}$ & $\begin{array}{c}\text { Carreteras } \\
\text { 3 orden }\end{array}$ & $\begin{array}{c}\text { Carreteras } \\
\text { Provinciales }\end{array}$ & Total \\
\hline $\mathbf{1 8 6 1}$ & 152,500 & 20 & 38 & - & 210,500 \\
\hline $\mathbf{1 8 6 2}$ & 154,500 & 45,500 & 40 & - & 240 \\
\hline $\mathbf{1 8 6 3}$ & 163,800 & 45,720 & 40 & - & 249,520 \\
\hline $\mathbf{1 8 6 4}$ & 88,212 & 132,415 & 40,127 & - & 260,754 \\
\hline $\mathbf{1 8 6 7}$ & 87,585 & 188,139 & 79,585 & - & 355,309 \\
\hline $\mathbf{1 8 8 8}$ & 88,71 & 273,408 & 115,347 & 76.914 & 554,379 \\
\hline
\end{tabular}

Fuente: Elaboración propia.

En relación a la situación de nuestra provincia con respecto a las diversas ciudades andaluzas, hay que destacar que Córdoba pasó de la cuarta posición en longitud de kilómetros de carreteras de primer orden por detrás de Jaén con $263.50 \mathrm{~km}$, Sevilla $257.50 \mathrm{~km}$ y Granada con $178.50 \mathrm{~km}$ a ocupar la tercera en 1888 con $88.710 \mathrm{~km}$ por detrás de Jaén con 241.546 y Sevilla $208.355 \mathrm{~km}$.

En el apartado de las calzadas de segundo orden, el auge constructivo supuso que la ciudad obtuviera el mayor porcentaje de kilómetros construidos en 1888 , con $273.408 \mathrm{~km}$ cuando en 1864 ocupaba la segunda posición por detrás de Jaén con $132 \mathrm{~km}$ en 1864. 
Por último, por falta de datos en algunas ciudades andaluzas no podemos ofrecer la evolución del kilometraje construido, salvo para el año de 1888 en el que el Anuario Estadístico Español sí recoge dicha muestra, por lo que sólo podremos analizar que Córdoba estaba emplazada en el séptimo puesto de las ciudades andaluzas con más vías de tercer orden: 115,347 km siendo Cádiz la que más tendido ofrecía con 222,150 km.

Por lo que hemos visto la ciudad de Córdoba presentaba un esquema viario bastante aceptable dentro de las posibilidades propias del periodo al que nos referimos, destacando que en estos años la situación geográfica privilegiada de la ciudad se vio reflejada por los diversos gobiernos que dotaron a la provincia de un trazado viario de vital importancia en relación a otras provincias andaluzas que tuvieron que esperar épocas venideras para satisfacer sus necesidades de interconexión. Otro factor reseñable y al que ya hemos aludido, es el referente a la preeminencia por parte de las élites gubernamentales de primar los centros neurálgicos de comercio y ciudades con una situación geo-estratégica que estimulase este fin por medio de un sistema de comunicaciones poco equitativo con respecto al global de la realidad nacional, pues muchas ciudades de la geografía española tuvieron que subsistir con caminos cuasi medievales hasta bien entrado el siglo XX.

\section{CONCLUSIONES}

En esta propuesta didáctica de práctica educativa hemos querido exponer la fundamentación teórica como punto de partida a la hora de realizar experiencias académicas para el alumnado de la asignatura de Didáctica de las Ciencias Sociales en el Grado de Educación Primaria.

Las documentaciones presentadas son fruto de una metodología colaborativa entre dos disciplinas como la Historia y la Didáctica de las Ciencias Sociales. En un primer momento la función del profesorado estaría encaminada a guiar al alumnado en la elaboración del dossier histórico recogiendo la información que crea más conveniente para el tipo de práctica que pueda plantearse: Itinerario didáctico, exposiciones, comparativas pasado-presente a través de imágenes... Esta metodología nos permite incentivar la transversalidad y el trabajo en equipo entre las disciplinas implicadas.

La realización de actividades de tipología como la presentada nos permitirá tratadas las competencias, no solo las inherentes a las áreas trabajadas, sino que también podrán fomentarse las digitales, sociales y cívicas... fruto del trabajo teórico-práctico del alumnado. 


\section{BIBLIOGRAFÍA}

- Anuario Estadístico Español, 1888, p. 403.

- BAYLEY, P., Didáctica de la Geografia. Madrid, Cincel-Kapelusz, 1981.

- BENAYAS DEL ÁlAMO, J., Paisaje y Educación ambiental. Evolución de cambios de actitudes hacia el entorno. Madrid, MOPTT, 1992.

- BENAYAS, J. y MARCÉN, C., Viviendo el paisaje. Guía didáctica para interpretar y actuar sobre el paisaje. Madrid. Fundación Natwest, 1994.

- BENEJAM, P., y otros, Las Ciencias Sociales, conceptos y procedimientos. Barcelona, Grao, 2002.

- BUSQUETS, J., La lectura visual del paisaje. Bases para una metodología. Iber,.$^{\circ} 9$ (1996)

- CORTÉS, A. M., La Interdisciplinaridad en la Educación Universitaria, en Anuario del CIJS. nº 10, sección 4 (2007) 401-415.

- CUÉLLAR VILLAR, D., Los Transportes en el Sureste Andaluz (1850-1950): Economía, empresa y territorio. Fundación historia de los ferrocarriles, Madrid 2003.

- DE BOlos CAPDeVILA, M., (dir.), Manual de Ciencia del Paisaje. Barcelona, Masson, 1992.

- ESTREMERA, P., La necesidad de una didáctica del paisaje en Geografia: los objetivos sobre valores y actitudes. I Congreso de Ciencia del paisaje. Universidad de Barcelona, 1990.

- Gaceta de Madrid, 6/V/1877.

- GARCÍA RUIZ, A. L. (dir.), Didáctica de las Ciencias sociales en la Educación Primaria. Sevilla, Algaida, 1993.

- GÓMEZ MENDOZA, A., "Las obras públicas, 1850-1935”, en COMÍN COMÍN F., y MARTÍN ACEÑA, P. (dirs.), Historia de la Empresa Pública en España. Madrid 1991, pp. 179-184. 
- HERNÁNDEZ, F. X., "Sociedad, Patrimonio y Enseñanza. Estrategias para el siglo XXI", en GONZÁLEZ GALLEGO, I. (dir.), La Geografía y la Historia, elementos del medio. Madrid, Ministerio de Educación, Cultura y Deporte. INSA, 2002, pp. 245-277.

- LÓPEZ, F., y SEGURA, J., "Los itinerarios didácticos: un recurso interdisciplinar y vertebrador del currículum. Espiral", en Cuadernos del Profesorado. Revista Digital del Centro de Profesorado Cuevas-Olula, Vol. 6, 12 (2013).

- LÓPEZ ONTIVEROS, A., Caracterización geográfica de Andalucía según la literatura viajera de los siglos XVIII y XIX, Córdoba 2001.

- MARTÍNEZ, F. J., y GARCÍA, A. J., "Itinerarios didácticos por Fuente Álamo (Murcia), una estrategia educativa de innovación en el proceso de enseñanza aprendizaje en educación secundaria", en Espiral Cuadernos del Profesorado, 1 (2008) 1-9.

- Revista de Obras Públicas, № 3388 (1999) 156. Decreto sobre la redacción de un nuevo plan de carreteras en España. 1886, 34, tomo IV, boletín, (18) $150-152$.

- SANTISTEBAN, A., y PAGÉS, J., "La educación democrática de la ciudadanía: una propuesta conceptual”, en ÁVILA, R. Mª.; LÓPEZ, J. R.; FERNÁNDEZ, E. (eds.), Las competencias profesionales para la enseñanza- aprendizaje de las ciencias sociales ante el reto europeo y la globalización, Bilbao, Asociación Universitaria de Profesores de Didáctica de las Ciencias Sociales, 2007, pp. 353-368.

- SANTOLARIA, A., "La ciudad como recurso didáctico", en EDETANIA. Estudios y Propuestas Socioeducativas, 45 (2014) 235-244. Recuperado a partir de: https://revistas.ucv.es/index.php/Edetania/article/view/189.

- VALVERDE, F.; SEQUEIROS, C., y LOMA, M., "La ciudad y el patrimonio urbano como forjadores de identidad", en ESTEPA J.; FRIERA, F., y PIÑEIRO, $\mathrm{M}^{\mathrm{a}} \mathrm{R}$. (coords.), Identidades y territorios: un reto para la didáctica de las Ciencias Sociales, Oviedo, KRK ediciones y Asociación Universitaria de Profesores de Didáctica de las Ciencias Sociales, 2001, pp. 579-586.

- VILARRASA, A., Salir del aula, Íber. Didáctica de las ciencias sociales, geografía e historia, 36 (2003). Dedicado a salir del aula. 